\title{
natureouTLOoK GOLD
}

14 March 2013 / Vol 495 / Issue No 7440

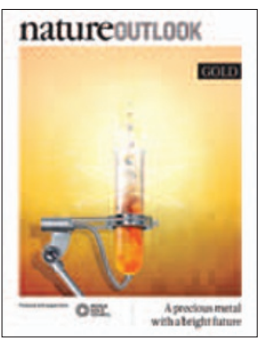

Cover art: Viktor Koen

Editorial

Herb Brody,

Michelle Grayson,

Tony Scully,

Nick Haines

Art \& Design

Wes Fernandes,

Nicola Hawes,

Alisdair Macdonald,

Andrea Duffy

Production

Karl Smart,

Susan Gray, Leonora

Dawson-Bowling

Sponsorship

Reya Silao,

Yvette Smith

Marketing

Elena Woodstock,

Hannah Phipps

Project Managers

Claudia Deasy,

Christian Manco

Art Director

Kelly Buckheit Krause

Publisher

Richard Hughes

Magazine Editor

Tim Appenzeller

Editor-in-Chief

Phil Campbell
$\mathrm{F}$ rom wedding rings on fingers to massive ingots in government vaults, by way of Olympic medals and stained glass windows, gold has been highly prized for millennia. Its contribution to metaphor alone is legion - who would want a therapy that is, let us say, the silver standard?

Element 79 in the periodic table has a celebrated place in the history of science and technology. Ernest Rutherford figured out the basic architecture of the atom - a tiny nucleus orbited by distant electrons - by shooting alpha-particles at gold foil and seeing that most went straight through it. Michael Faraday's experiments with colloidal gold gave an early hint of today's nanotechnology revolution. And gold electrodes were used in the earliest integrated circuits - the chips that launched the information revolution.

The rising price of gold has driven mining companies to places previously deemed too difficult or expensive, and recycling plants extract large amounts of gold from discarded mobile phones, computers and other electronic jetsam (see page S4). Microorganisms can help too - bacteria have been found that make gold nanoparticles from solutions of gold salts (S12).

Nanoparticles are at the heart of gold's most exciting technological developments. Gold nanoparticles can carry drugs directly to tumours without damaging healthy tissue (S14), for example. The striking visual qualities of gold hint at remarkable properties found only at extremely small dimensions. The so-called plasmonic effect, which gives stained glass windows their iridescent beauty, is especially pronounced when using gold (S7); this property could lead to better electronic and photonic devices, such as more efficient solar cells (S8). And chemists are discovering that although gold is usually chemically inert, it can be an extremely effective catalyst (S10).

We acknowledge the financial support of the World Gold Council in producing this Outlook. As always, Nature has full responsibility for all editorial content.

\section{Herb Brody}

Supplements Editor

\section{CONTENTS}

\section{S2 RESOURCES}

Mine, all mine!

An eye on the prize

S4 MINING

Extreme prospects

Getting deep and dirty in the search for gold

S7 PERSPECTIVE

\section{A glint of the future}

Anatoly V. Zayats looks through the stained glass window

S8 PHOTONICS

Trick of the light

Plasmonic resonance has a bright outlook

S10 CATALYSIS

The accelerator

Developing quicker reactions

S12 MICROBIOLOGY

There's gold in them there bugs

Microbial alchemy takes centre stage

S14 BIOMEDICINE

The new gold standard

Nanoparticles can image, diagnose and treat disease

\section{COLLECTION}

S17 The promoting effect of adsorbed carbon monoxide on the oxidation of alcohols on a gold catalyst

Paramaconi Rodriguez, Youngkook Kwon and Marc T. M. Koper

S23 Nanoparticles that communicate in vivo to amplify tumour targeting Geoffrey von Maltzahn et al.

S31 Optical detection of single non-absorbing molecules using the surface plasmon resonance of a gold nanorod Peter Zijlstra, Pedro M. R. Paulo and Michel Orrit

interest and debate around a subject of interest to the sponsor, while satisfying the editorial values of Nature and our readers' expectations. The boundaries of sponsor involvement are clearly delineated in the Nature Outlook Editorial guidelines available at http://www. nature.com/advertising/resources/pdf/outlook_guidelines.pdf CITING THE OUTLOOK

Cite as a supplement to Nature, for example, Nature Vol XXX, No. XXXX Suppl, Sxx-Sxx (2013). To cite previously published articles from the collection, please use the original citation, which can be found at the start of each article.

VISIT THE OUTLOOK ONLINE

The Nature Outlook Gold supplement can be found at http://www.

nature.com/nature/outlook/gold_2013/

All featured articles will be freely available for 6 months SUBSCRIPTIONS AND CUSTOMER SERVICES For UK/Europe (excluding Japan): Nature Publishing Group, Subscriptions, Brunel Road, Basingstoke, Hants, RG21 6XS, UK. Tel: +44 (0) 1256329242 . Subscriptions and customer services for Americas - including Canada, Latin America and the Caribbean Nature Publishing Group, 75 Varick St, 9th floor, New York, NY 10013-1917, USA. Tel: +1 8663637860 (US/Canada) or +1 212726 9223 (outside US/Canada). Japan/China/Korea:Nature Publishing Group - Asia-Pacific, Chiyoda Building 5-6th Floor 2-37 Ichigay Tamachi, Shinjuku-ku, Tokyo, 162-0843, Japan. Tel: +81 33267875 CUSTOMER SERVICES

Feedback@nature.com

Copyright $\odot 2013$ Nature Publishing Group
\$35 A high-throughput drug screen for Entamoeba histolytica identifies a new lead and target Anjan Debnath et al.

S40 An invisible metal-semiconductor photodetector

Pengyu Fan et al. 